\title{
Artigos
}

\section{Identidades Étnicas, Irmandade do Rosário e Rei do Congo: sociabilidades cotidianas recifenses - século XIX}

Marcelo Mac Cord No Recife oitocentista, podemos rastrear algumas importantes nações africanas consorciadas com as irmandades religiosas e sociabilidades correlatas. Por isto, preliminarmente, é importante observarmos as principais referências étnicas presentes nas freguesias do Recife. No período estudado, encontramos, basicamente, escravos provenientes do congo, de angola e da costa da mina - termos que apareciam constantemente entre os homens pretos na cidade.

Corroborando esta concepção sobre as nações que preponderaram no Recife, temos alguns dados de René Ribeiro sobre os negros em Pernambuco. Mesmo que faça um estudo de maneira muito mecanicista, além de afirmar a existência de ciclos no tráfico, o autor confirma que, provavelmente, tivemos um determinado equilíbrio entre os angola e os vindos da costa da mina até o fim do tráfico ao Norte do Equador, em 1815. A partir desta data houve uma hegemonia do primeiro grupo, nas referidas entradas. $\mathrm{O}$ autor ainda afirma que entre os angola estava incluído um importante contingente dos congo, grupo também pertencente às culturas bantu ${ }^{1}$ (Ribeiro 1948/ 49:15-17).

Roquinaldo Ferreira nos contempla com dados mais precisos, afirmando que, mesmo antes de 1815, "no Brasil, a escravidão tinha grande dependência em relação ao Congo-Angola. Entre 1701 e 1810, 68\% dos escravos trazidos para o Brasil foram embarcados por Luanda e Benguela" (Ferreira 1997:4). Após este período, ainda nos anos de 1810, com o Congresso de Viena e a concordância do governo português na eliminação do tráfico ao norte do Equador, o tráfico de escravos procedentes desta região da África diminuiu ainda mais. Marcus Carvalho afirma que o apogeu do tráfico a partir de Angola, para Pernambuco, aconteceu após 1815 (Carvalho 
Assim, a participação centro-africana no fornecimento de braços foi a mais significativa entre 1815 e 1850, concentrando ainda mais os grupos de procedência Congo/Angola no Brasil, oriundos de "Estados como Angoi, Congo, Cacongo e Loango" (Florentino 1995:89). Roquinaldo Ferreira afirma que "na primeira metade do século XIX, o Congo-Angola manteve uma participação por volta de $70 \%$ no tráfico de escravos com o Brasil" (Ferreira 1997:5), seguindo uma tendência já apresentada no século XVIII.

Além da proibição do tráfico ao Norte do Equador, surgiu outro importante fator que ajudou a recrudescer o tráfico ao sul da referida linha imaginária (ou seja, na África central Atlântica), que foi a guerra civil no Reino do Congo. Estes foram dois relevantes fatores na oferta de mão-de-obra escrava, aos traficantes, na primeira metade do século XIX. Segundo Thornton, o processo da guerra civil e o impacto demográfico por ela ocasionado, entre 1718 e $1844^{2}$, mais especificamente no final do século XVIII, somavam-se, conformando um contingente populacional reunido a partir de quatro grandes movimentos básicos:

“a) as guerras geralmente conduzidas entre pretendentes ao trono; b) os conflitos em menor escala que se confundiam com o banditismo, mas que também estavam ligados a questões políticas das guerras civis; c) as guerras entre aldeias causadas por rivalidades locais e dívidas não pagas e que não estavam relacionadas diretamente com as guerras civis, mas que talvez fossem causadas pela ruptura das reparações judiciais; e d) o banditismo local e a escravidão judicial" (Thornton 1997:59)

No caso pernambucano, quanto às gentes lá aportadas durante a primeira metade do século XIX, observase que uns fatores foram mais preponderantes que outros, destes que Thornton enumerou. Segundo Marcus Carvalho, a maior parte deste montante nas entradas foi formada por crianças, agricultores e pastores. Estes "não eram prisioneiros de guerra - e no caso soldados - mas vítimas de sistemas tributários nos quais as moedas eram pessoas" (Carvalho 1998: 179). Certamente, são casos que podem ser enquadrados no que Thornton qualifica como escravização por reparação judicial, mesmo que ligadas diretamente à guerra.

O movimento do tráfico trouxe para Pernambuco, principalmente no século XIX, portanto, uma representativa presença congo/angola. De qualquer forma, cremos que a preponderância deste grupo não homogenize suas experiências no Recife, criando positivamente uma identidade étnica solidária e impenetrável. Sabemos que estas procedências não representavam de forma determinante uma identidade africana, mas indicavam as regiões de embarque dos escravos para o Brasil. O próprio termo genérico cria uma absolutização étnica que não é salutar para os estudos sobre a escravidão no Brasil, como indicam as obras mais recentes sobre o tema.

Ao invés de nações, referidas classicamente pela historiografia, preferimos, como Mariza Carvalho Soares, utilizar o termo pensando nos "grupos de procedência". Este conceito permite marcar que, no tráfico, a saída de um grupo de africanos de um porto na África não homogeneizava suas identidades e experiências na escravidão. O local de saída podia servir, sim, como referência ao grupo na sua nova experiência em terras americanas, quer na sua relação com os brancos, quer na sua relação com outros negros. Assim, quando um livre, liberto ou 
escravo, no Recife, dizia ser congo, angola ou costa, isto "não corresponde necessariamente a um grupo étnico, podendo ser resultado da reunião de vários grupos étnicos que são embarcados num mesmo porto" (Soares 1997:82).

Robert Slenes dá-nos uma primeira pista da problematização destes padrões étnicos muito generalizantes, principalmente quando o referencial está ligado aos padrões culturais bantu, quando afirma que "os termos 'Congo/Angola', evidentemente, abarcam uma extensa região costeira da África e um sertão enorme" (Slenes 1999:246). A diversidade espacial foi tão significativa que Miller afirma, ao referir-se a Angola central e do sul, que os variados padrões demográficos e lingüísticos não deixaram de estar ligados a ela (Miller 1997: 11). Algo semelhante é descrito por Mary Karasch, quando diz que, no século XIX, a África central era "comumente dividida em três regiões principais: Congo Norte (Cabinda), Angola e Benguela. Porém o significado desses termos variava muito e o uso deles no tráfico de escravos não era consistente com a verdadeira identidade étnica" (Karasch 2000:50).

Apesar de Mary Karasch tratar, por exemplo, o Rio de J aneiro como "cidade africana", a autora problematiza a densidade das identidades monolíticas do congo e de angola, encontrando na referida cidade oitocentista uma série de outras referências étnicas. Por exemplo, do Congo Norte temos os cabinda e os congo, do Norte de Angola os angola e os rebolo e do Sul de Angola os benguela e os canguela (Karasch 2000:46). No Recife encontramos padrões semelhantes.

A pretensa tranqüilidade do termo congo/angola esconde também outro problema crucial. Virgílio Coelho, antropólogo angolano, afirma que:

“na primeira fase de contato que os portugueses estabeleceram com o Ndòngò [Angola] parece ter havido uma tendência de equiparar ou para desvirtuar a informação em função do Reino do Congo, onde estes estiveram pela primeira vez. Tendo conhecido e vivido no Reino do Congo e na Mbànzà real, a tendência geral dos portugueses foi a de ver tudo em função desse país, como se tratassem de continuidade territorial e até de línguas e culturas idênticas" (Coelho 1997: 138)

Desta forma, por mais que afirmemos a proximidade das culturas bantu, o termo congo/angola não pode ser abordado como algo auto-referente. Destas considerações, certamente, podemos concluir que se grande parte daqueles africanos escravizados que aportaram no Recife (de finais do século XVIII até o fim da primeira metade do XIX) partilhava elementos culturais e sociais dos tempos anteriores à diáspora, isto não representava uma identidade monolítica em terras pernambucanas.

Feitas as considerações preliminares, os grupos étnicos, junto do corporativismo e das solidariedades 
profissionais, foram tradicionalmente fundamentais tanto na organização da Irmandade do Rosário dos Pretos de Santo Antônio do Recife (no cotidiano das suas políticas confraternais)³, quanto nas "hierarquias do Rei do Congo" (grupo social paralelo e subordinado ao do Rosário, mas que também abrangia outras confrarias negras da cidade). Apesar da visibilidade das identidades étnicas ocorrer nestas instâncias, por exemplo, desde o século XVII, devemos ressaltar que estas foram forjadas, apropriadas e transformadas em cada conjuntura histórica. É sobre esta plasticidade e tensão identitária que versa este artigo.

Sendo assim, não podemos deixar de sublinhar que a informação étnica bantu surgiu no próprio título real do soberano negro. O reinado das ruas recifenses, e dos seus arredores, nos remeteu a uma espacialidade e a uma identidade com referenciais centro-africanos. Por mais que estas marcas tivessem sentidos diversos daqueles vividos em África, não podemos deixar de perceber tal gramática e a sua força nas sociabilidades criadas em Pernambuco.

Ao tomarmos as "hierarquias do Rei do Congo", referidas no Compromisso da Irmandade do Rosário dos Homens Pretos de Santo Antônio do Recife de 1758, espécie de contrato entre seus confrades, observamos que o reinado deveria ter como soberano um membro da nação angola - ou seja, um bantu. Este grupo étnico devia ter, portanto, a precedência dentro e fora da igreja do Rosário. Desta forma, os angola comandariam as referidas hierarquias, com seus braços políticos e profissionais, além de provavelmente ocuparem os principais cargos da Mesa Regedora do Rosário - sua instância deliberativa.

A hegemonia dos angola no reinado fora construída desde o século XVII, mais precisamente logo após a Restauração Pernambucana. Com a retomada de Pernambuco pelos reinóis lusitanos, segundo Leonardo Dantas da Silva, as alianças entre o Reino do Congo (na África) e a Holanda foram consideradas ofensivas aos interesses da Coroa Portuguesa. Por causa disto, eles fizeram com que não se coroassem mais Reis do Congo entre os confrades irmanados no Rosário dos Homens Pretos de Santo Antônio do Recife (Silva 1988a: 18-23).

Nos manuscritos da Irmandade da referida invocação, em 1675, logo vinte e um anos depois da expulsão dos holandeses das terras pernambucanas, temos realmente a confirmação da presença do Rei e da Rainha Angola no lugar do título de soberano dos Congos (Silva 1988b:126). Algum tempo depois deste fato, o título Rei do Congo voltou a ser concedido normalmente, sendo reconhecido novamente em sua plenitude no transcorrer do século XVIII. De qualquer forma, como vimos anteriormente, o Rei continuava, oficialmente, a ser um angola, apesar da referência do título real ser do congo.

A partir de finais do século XVIII e inícios do XIX, não podemos afirmar precisamente a preponderância de qualquer grupo étnico no reinado (neste período, as "hierarquias do Rei do Congo" foram proibidas oficialmente 
vivo nas ruas do Recife e no cotidiano da Irmandade do Rosário). A mesma observação pode ser feita tendo em vista a Mesa Regedora da Irmandade. Por exemplo, o Compromisso de 1870 deixou evidente a necessidade de haver equanimidade funcional entre os seus vogais negros nacionais e africanos.

Ao falar em africanos, o documento criou uma generalização que não considerou as diferentes etnias presentes na confraria. Além disto, a referida fonte não fez quaisquer restrições étnicas, mas sociais e pecuniárias, nas matrículas de seus irmãos. Ao contrário, o Compromisso de 1758 havia criado uma predileção muito específica para a entrada dos grupos étnicos angola e da costa nos seus quadros, não generalizando as entradas para todo e qualquer preto. Comparativamente, Mariza Carvalho Soares, para o mesmo período, tendo como locus o Rio de J aneiro, afirmou que "os africanos da Costa da Mina, excluídos das esferas de poder das irmandades do Rosário, resolveram criar suas próprias agremiações" (Soares 1997:172).

Apesar da generalização, africanos, que se instituía no transcorrer dos novecentos, a marca étnica não arrefeceu instantaneamente. No ano de 1852, no dia 10 do mês de outubro, ocorreu, como em todos os anos, a concorrida festa da Senhora do Rosário dos Pretos da freguesia de Santo Antônio. Segundo Fernando Pio, este festejo foi um dos mais importantes que marcaram a proximidade do Natal recifense. Naquela data, dedicada também à procissão da Padroeira, "as nações africanas saiam em grupos compactos, cada uma trazendo o seu governador à frente, vestido à militar e acobertado por uma imensa umbrela" (Pio 1935:20-23) - as citações seguintes referem-se a esta nota.

Os governadores que seguiam à frente faziam parte do que chamamos de "hierarquia do Rei do Congo". Tais Governadores de Pretos comandam tanto grupos étnicos quanto profissionais (podendo haver interfaces entre etnia e ofício, ou seja, determinado grupo étnico controlando uma profissão qualquer) e estão subordinados diretamente ao soberano. Percebemos claramente a representatividade das patentes negras. Apesar da sua anunciada informalidade e proibição, o exercício de poder, com os Governadores de Pretos em grande destaque, à frente aos seus subordinados, se manteve com densa efetividade. Quanto à caracterização militar, além da disciplina, pode ser provavelmente uma referência ao tradicional Terço dos Henriques, outra importante instância de poder dos homens pretos consorciada ao reinado e às irmandades 4 .

$\mathrm{Na}$ frente de todas aquelas nações, com os seus respectivos Governadores, coroando a procissão de Nossa Senhora do Rosário dos Homens Pretos com as hierarquias estabelecidas, alguém surgiu. Ratificando a sua representatividade social, “como um autêntico príncipe africano, marchava a figura possante de um negro [...]: era o rei da nação Conga, a única que gozava do privilégio de eleger um rei ${ }^{5}$ cuja atuação estendia-se também sobre as demais nações africanas". Neste período, o rei era D. Antônio de Oliveira Guimarães. J unto dele, segundo Fernando Pio, havia uma grande e imponente Corte. Contudo, sobressaía, no meio de todos aqueles majestosos 
negros, "o vulto do capataz, encarregado dos negros trabalhadores da estiva".

O festejo transcorria aparentemente com toda a ordem. Imaginamos o estourar de fogos de artifício, a oferta de comidas sendo vendidas por negras boceteiras e a espera pela hora da missa, por exemplo. Num determinado momento, circulou um boato, pelas ruas em que passava a procissão, que gerou muito pânico entre os brincantes/devotos. Passantes afirmaram que haviam aberto um curral nas proximidades do largo das Cinco Pontas e um touro bravo escapara, criando muitos problemas na vizinhança, especialmente pela povoação dos Afogados.

Todos temeram que ele chegasse à freguesia de Santo Antônio e, especialmente, às ruas próximas à igreja do Rosário dos Homens Pretos e, com sua fúria, estragasse o préstito. Entrementes, conforme o festejo se desenrolava, no Pátio da importante e central Igreja do Carmo ocorreu o inesperado e casual encontro entre duas nações, "a dos Cassanges e a dos negros de Cabundá", que começaram uma disputa por "primazia" no folguedo, que entendemos como um conflito de poder no reinado. Talvez, o jogo da disputa fizesse parte do ritual, como no jongo, por exemplo, onde encontramos cantos improvisados, "freqüentemente incluindo desafios, ou 'pontos' (enigmas) para serem 'desamarrados'” (Slenes 1991/92:61).

A altercação por prioridade na festa se desenrolava (talvez com cantos e/ou danças e/ou gritos e/ou ameaças físicas e morais) quando, de repente, "um grito estrangulado paralisou a contenda" (Pio 1935:23). O touro, que naquele momento já corria alucinadamente pelas ruas centrais do Recife, entrou enfurecido no meio das duas nações pondo todos em fuga. No meio da confusão, ao tentar dominar o animal (talvez num gesto de prova de coragem e força, ou por ter sido simplesmente encurralado), o governador dos cassange morreu a chifradas.

Ressaltamos, neste caso, que ambos os governadores, e suas respectivas nações, estavam ligados, usando os termos de Mary Karasch, às referências culturais e espaciais da "africanidade central" (Karasch 2000:36). Os conflitos de 1852 ocorreram num reinado aparentemente sem grandes disparidades culturais (em vista da origem centro-africana comum dos grupos em questão, de um bom convívio interétnico provável na Irmandade do Rosário e na ocupação paritária das "hierarquias do Rei do Congo"). Entretanto, tais conflitos não nos causaram espanto, pois se determinados grupos étnicos estabeleceram "lealdades primárias", em função de afinidades culturais muito profundas, isto não representou que elas fossem primordiais (Oliveira 1998:282). Em outras palavras, não há determinações naturais ou essenciais na organização dos grupos étnicos.

É por isto que não há contradição na fratura de solidariedades étnico-culturais, seja no "pequeno grupo", como angola, cassange, cabunda, ou no "grupo maior", representado pela cultura bantu. A identidade étnica surge, portanto, como uma efetiva construção política (Weber 1994:274). Por este motivo, ela não foi um conjunto 
atemporal ou imutável de traços essenciais aos grupos humanos em Pernambuco. Por mais que as identidades étnicas mexessem com sentimentos profundos de pertencimento, elas não devem ser entendidas como a mais pura ou primordial das formas de reconhecimento social, mas sim como uma das possíveis formas de organização social (Barth 1969:13).

As identidades étnicas foram sendo manipuladas de acordo com as necessidades, limites sociais, sensibilidade para percebê-las e expectativas dos atores recifenses, sendo tão problemática a sua análise como a de qualquer outro aspecto da história social. Assim, as identidades dos indivíduos ligados à cultura bantu (que fizeram parte das "hierarquias do Rei do Congo" e da Irmandade do Rosário dos Pretos de Santo Antônio do Recife) não puderam ser definidas a priori, porque esta cultura não foi uma informação imanente às suas vidas (Poutignat \&Streiff-Fenart 1998: 110). Os seus integrantes não estiveram amalgamados por "lealdades primordiais" ${ }^{6}$.

Para estes grupos, finalmente, como vimos no caso analisado, mesmo que estivessem alinhavados pela "marca" bantu, não havia garantia de uma coordenação natural de ações e expectativas nas suas políticas e estratégias (quando o assunto foi o universo confraternal ou o reinado). É por este motivo que a identidade étnica, enquanto parâmetro de análise, não deve ser pensada isoladamente de outras instâncias sociais (como gênero, classe, estamento ou quaisquer outras categorias que nos remetam ao sentido de pertencimento). Ela foi uma das formas, "em meio a outras escolhas de identificação possíveis" (Poutignat \&Streiff-Fenart 1998:64), que os negros puderam manipular na vida social recifense. As políticas confraternais, tal qual as "hierarquias do Rei do Congo", foram constituídas por uma teia, na qual os grupos étnicos se apresentavam apenas como um de seus importantes fios.

A própria abrangência da soberania do reinado, no Recife, ampliou ainda mais a problemática das "lealdades primárias", estendendo-as para fora do grupo bantu. O reinado de Domingos do Carmo, nos primeiros anos da década de 1810, por exemplo, incluía na linha de ascendência do Rei do Congo o controle de "todas as Nações do Gentio da Guiné" (Torres 1997:95). Este termo, tradicionalmente, foi uma expressão portuguesa para se referir genericamente aos africanos, sendo utilizada desde o século XVI (Oliveira 1997:37). Caso semelhante ocorreu com o próprio D. Antônio de Oliveira Guimarães, também referido como comandante das “demais Nações existentes nesta Província"7 (informação ratificada também por Fernando Pio, em citação supra).

Para entendermos a amplitude da soberania da coroa, e a extensão de seus domínios, devemos retornar, novamente, um pouco no tempo. O reinado aglutinou, por causa desta generalidade de comando, desde o século XVIII, sob a ascendência do Rei do Congo, que era angola, uma série de outros grupos étnicos que não faziam parte da cultura bantu. Por exemplo, ainda nos setecentos, apontamos a presença de Governadores de Pretos como sobaru e ardas, patenteados em 1776, submetidos igualmente à Coroa do Rei do Congo como qualquer 
outro Governador de Preto do grupo bantu. Há também, para este período, referências a patenteados da “Nação Dagome" (Silva 1999:87) submetidos diretamente, também, ao mesmo soberano.

Na classificação do tráfico, os grupos acima descritos estiveram associados ao etnônimo costa da mina, também chamados simplesmente de mina ou de costa (esta referência foi utilizada, com freqüência, em Pernambuco, para os negros traficados daquela porção do continente africano). Segundo Maria Inês Côrtes de Oliveira, eram chamados assim, "no Brasil do século XVIII, [os] africanos que eram embarcados na Costa do Leste ou Costa a Sotavento do Castelo de São J orge da Mina. Esta fortaleza estava localizada na Costa do Ouro, atual Gana" (Oliveira 1997:58). Tal qual o etnônimo bantu, ser costa da mina não representava uma homogeneidade cultural ou o pertencimento somente a um grupo étnico (Karasch 2000:64).

Os costa da mina, pensados também como uma grande nação, portanto, foram identificados levando-se em consideração suas diferenças frente aos grupos da África Central. Como exemplo disto, temos uma passagem de Debret, feita no início do século XIX, em missão artística no Brasil, na qual afirma que os costa da mina seriam todos aqueles que não pertenciam ao grupo bantu (Oliveira 1997:61). Segundo Barth, este tipo de atitude é muito comum nas classificações dos grupos étnicos, pois eles são identificados pelo contraste, ou seja, pela criação de fronteiras que instituem as noções do eles/nós (Barth 1969:13).

As diferenças entre os grupos existiram, sem dúvida. Entretanto, devemos fugir de idéias como o “mito da comunidade natural, o mito do sangue e da raça" (Heller 1992: 81). Houve, portanto, uma flagrante tensão entre as "lealdades primárias" e o trânsito pelas fronteiras étnicas. A África, no Brasil, teve que se transformar. Entretanto, as solidariedades primárias, intra ou extragrupos étnicos, estiveram no bojo dos acontecimentos sociais. Não podemos negar que as "lealdades primárias", mesmo que relativas, motivaram as ações dos homens negros ligados aos referidos grupos etnolingüísticos/culturais. Segundo J oão J osé Reis, o conjunto de diferenças entre os costa da mina e os bantu, pelo país, se originou justamente por causa das suas distintas formações sócioculturais e econômicas na África (Reis 1986:187). Este é um dado importante e também deve ser levado em conta.

Retornando agora ao Rei do Congo, D. Antônio de Oliveira Guimarães, encontramos conflitos muito sérios entre alguns indivíduos referidos como costa e o reinado. Isto não pode representar uma resistência natural da referida nação ao poder daquele soberano bantu. Basta lembrar, no mesmo sentido, que nem todos os bantu seguiram as hierarquias do reinado de forma tranqüila, como vimos no caso da festa de 1852. Concordamos plenamente com J oão J osé Reis, quando afirma que foi "improvável que a maioria dos africanos levasse assim tão a sério suas diferenças étnicas" (Reis 1986:26), pois eles viveram precisando operar convenientemente outras formas identitárias. 
Podemos perceber isto claramente numa reunião da Mesa Regedora da Irmandade do Rosário dos Pretos da freguesia de Santo Antônio do Recife, aos 27 de janeiro de 1861, com todos os "Governadores das Nações Africanas". Apesar de suas diferenças étnicas e conflitos de precedência no conturbado reinado de D. Antônio de Oliveira Guimarães, superando possíveis querelas cotidianas e/ou históricas, recolheram e doaram a quantia de $39 \$ 460$ réis àqueles mesários. Estes a repassariam ao Bispo, em homenagem ao "Santo Padre Pio IX"8. As conveniências sociais, aqui, falaram mais alto que as disputas étnicas cotidianas, portanto.

Estes complexos entrecruzamentos identitários, no reinado em questão, ainda contaram com um outro importante elemento social: o crioulo. O descendente de africano, nascido no Brasil, surgiu com importância nas políticas confraternais da Irmandade do Rosário no mesmo período em que foi coroado o Rei e a Rainha Angola (no século XVII). Naquela oportunidade também foram coroados o Rei e a Rainha dos Crioulos (Silva 1988b:126). Começamos a perceber, a partir disto, uma diferenciação substancial no perfil dos confrades e dos mesários.

Esta divisão aprofundou ainda mais o problema identitário no Recife. No período do reinado de D. Antônio de Oliveira Guimarães, ela se expressa através das já citadas disputas entre "africanos e nacionais", tal como apontou o Compromisso de 1870, que determinou a mistura dos dois grupos nos cargos da Mesa Regedora. Do contrário, teríamos a nulidade desta instância deliberativa. É bastante plausível que um aumento do número de crioulos, na Irmandade do Rosário dos Pretos, tenha criado esta demanda e também forçado a própria exigência para a entrada de irmãos desta origem. Percebemos, com isto, mais uma vez, que as questões étnicas se transformaram no transcorrer do tempo, não sendo possível supor uma linearidade tranqüila na história da confraria.

Estes limites entre "africanos e nacionais" eram também bastante difíceis de serem demarcados. É ingênuo acreditarmos que as classificações boçais e ladinos, para os primeiros, e crioulos, para os outros, expressavam definitivamente a identidades dos negros ${ }^{9}$. Agindo assim, arriscamos cometer o mesmo erro de afirmarmos a positividade dos grupos étnicos congos, angola e costa da mina. O primeiro caso, que nos colocou de frente com a questão anunciada, surgiu ao buscarmos determinar as características étnicas de D. Antônio de Oliveira Guimarães.

Variadas pessoas (inclusive ele próprio) apresentavam-no com identidades diferenciadas. No seu termo de posse, publicado no Diário de Pernambuco de 20 de setembro de 1848, quando foi referendado como Rei do Congo, ele apareceu definido pelo Chefe de Polícia como "preto liberto"10. Em finais de setembro de 1849, o próprio soberano, requerendo permissão para os festejos da Padroeira ao Chefe de Polícia, não informou a sua identidade étnica ou condição social ${ }^{11}$. Este, por sua vez, levando o pedido ao Governador da Província, em primeiro de outubro, classificou-o simplesmente como preto ${ }^{12}$. Finalmente, em outubro de 1851, a Câmara Municipal do Recife apresentou-o ao Chefe de Polícia como preto africano ${ }^{13}$. 
Estas classificações certamente não foram gratuitas e pensamos nos seus significados. Excetuando a ausência do dado étnico ou social na sua autodefinição, todas as classificações, feitas pelas diversas autoridades envolvidas, nos remeteram para os possíveis significados do termo "preto". Segundo Hebe Maria Mattos, ele "é sinônimo de escravo" (Mattos 1998:130) e "até a primeira metade do século [XIX], era referido preferencialmente aos africanos" (Mattos 1998: 30).

Temos aqui uma questão interessante. Assumindo estes padrões para o caso pernambucano, poderíamos afirmar primeiramente que aquele soberano era africano. Desta forma, se a sua coroação seguiu as tendências anunciadas no Compromisso de 1758, ele era oriundo do grupo étnico angola. Provavelmente tenha passado também pela experiência da escravidão, pois foi qualificado como liberto na sua referendação. A liberdade era também condição do reinado. Contudo, ele também apareceu simplesmente como preto, mas não cremos que fosse mais escravo naquele ano de 1849, segundo a própria notícia do Diário de Pernambuco do ano anterior quando foi referendado Rei do Congo. Em 1851, ele aparecia como preto africano, uma redundância se não podemos encontrar "pretos nacionais", pois estes eram chamados de crioulos. Na segunda metade dos oitocentos, talvez, o termo "preto", no Recife, tivesse já um significado diferente do apontado por Hebe Maria Mattos.

Ainda podemos encontrar mais problemas com duas comparações. A incidência de sobrenomes foi muito pequena e restrita entre os negros livres e libertos. No caso baiano oitocentista, somente $10 \%$ dos livres e libertos os possuíam (Silva 1997:203). Retomando Hebe Maria Mattos, existiram referências claras à associação entre a condição de libertos e a presença de sobrenomes nos seus registros. Isto, já num período posterior ao ano de 1888 (Mattos 1998:294). Ela ratifica sua afirmação ao concluir que, neste período, "foi extremamente difícil identificar os recém-libertos, pela ausência de sobrenomes" (Mattos 1998:333).

Levando todos estes dados em consideração, podemos talvez afirmar a origem africana do soberano. Entretanto, D. Antônio de Oliveira Guimarães sempre apareceu referido com seus dois sobrenomes. Ele ainda foi J uiz Perpétuo da Irmandade, o que representou possuir visível distinção intra e extramuros da igreja, o que dificilmente foi conquistado por alguém que fora escravo há bem pouco tempo. Cremos também que ele possa ter se apropriado da identidade de preto liberto e/ou africano para poder assumir uma coroa tradicionalmente dada a alguém de nação. Esta conjectura é bastante viável.

A manipulação da identidade étnica e/ou social não foi algo incomum no cotidiano dos negros no Recife. Nos movimentos revoltosos de 1817 e nos que antecederam a Confederação do Equador, ocorrida em 1824, podemos encontrar a destacada participação do "mestiço" Pedro Pedroso. Especialmente em 1823, ele foi acusado de insuflar uma insurreição com inspiração no "haitianismo". Para aliciar politicamente a população não-branca da 
(Costa 1984:62). Reconhecido publicamente como mestiço, conseguia transitar por irmandades de perfis diferenciados, seja como nacional, seja como africano.

Percebemos, com isto, que no próprio espaço confraternal as identidades étnicas e sociais foram flexíveis. O conflito entre uma identidade africana e outra nacional, nestes dois casos, cremos, foi menos um conflito entre negros efetivamente nascidos no Brasil ou na África do que a manipulação de identificações possíveis, para a obtenção de vantagens pessoais ou grupais, em determinadas situações cotidianas. Tollenare, em 1817, nos deixou pistas interessantes sobre este tipo de comportamento. Ele afirmou que os negros que conseguiam al guma projeção, no Recife, dissolviam as demarcações entre as cores (Tollenare 1978:113).

$\mathrm{Na}$ verdade, ele falava da ruptura e do trânsito entre alguns espaços sociais que tradicionalmente eram destinados aos negros e aos brancos. Isto se deu por causa da manipulação clara da identidade étnica. Ela pode ter sido feita com base em elementos físicos, até mesmo porque "a passagem de uma cor a outra se faz por uma escalada de que a vista mal pode contar todos os graus" (Tollenare 1978: 114), ou por questões sociais, porque "com um pouco de dinheiro [os negros] passam por mulatos escuros" (Tollenare 1978:114).

Perceber estas estratégias de sobrevivência, no universo das sociabilidades confraternais recifenses, tendo como mote a plasticidade das identidades étnicas, pode ajudar-nos a redimensionar algumas discussões sobre a questão racial no Brasil. Observamos que os espaços das sociabilidades da população não-branca, ao menos no que diz respeito ao nosso objeto de pesquisa, foram extremamente complexos. A Irmandade do Rosário dos Pretos da freguesia de Santo Antônio do Recife e as "hierarquias do Rei do Congo" não poderão ser analisadas simplesmente como espaços tolerados ou concedidos aos atores sociais em questão. Ao mesmo tempo, as perspectivas da conquista e do conflito social, tendo como fundamento a relação direta entre classe e raça, naqueles espaços, não nos parecem absolutamente pertinentes. Fazemos tal afirmação porque as ações dos confrades do Rosário e dos patenteados nas "hierarquias do Rei do Congo" apontaram para a problematização da homogeneidade de expectativas da população recifense não-branca, nos oitocentos. Em contrapartida, afirmar também que a ausência de tal homogeneidade foi negativa porque contribuiu para o enfraquecimento da "consciência negra", frente aos dominantes, também parece-nos algo frágil. Enfim, como mesmo afirmou Nietzsche, "não existem fenômenos morais, mas uma interpretação moral dos fenômenos" (Nietzsche /s.d./:85).

Marcelo M ac Cord é mestre em História pela UNICAMP e recebeu a $M$ enção Honrosa do Concurso Silvio Romero, promovido pela FUNARTE (2002) 


\section{NOTAS}

1 "Banto, s.m. Cada um dos membros da grande família etnolingüística à qual pertenciam, entre outros, os escravos no Brasil chamados angolas, congos, cabindas, benguelas, moçambiques, etc, e que engloba inúmeros idiomas falados, hoje, na África Central, CentroOcidental, Austral e parte da África Oriental./// adj. Pertencente ou relativo aos bantos ou às suas línguas - Do termo multilingüístico bantu, plural muntu, pessoa, indivíduo" (Lopes /s.d./:43).

2 Devemos salientar que, entre tais marcos temporais, para o autor referido, encontramos singularidades que não permitem criar continuidades, nos padrões do tráfico, de forma simplista ou mecânica.

3 Existe uma importante bibliografia sobre irmandades de homens pretos. Virgínia Maria de Almoêdo de Assis, Pretos e Brancos: a serviço de uma ideologia de dominação (caso das Irmandades do Recife), Recife, UFPe, 1988, dissertação de mestrado; Caio César Boschi, Os Leigos e o Poder: Irmandades leigas e política colonizadora em Minas Gerais, São Paulo, Ed. Ática, 1986; Elizabeth W. Kiddy, Brotherhoods of Our Lady of the Rosary of the Blacks: community and devotion in Minas Gerais, Brazil, New Mexico, University of New Mexico, 1998, tese de doutorado; Marina de Mello e Souza, Os Reis Negros no Brasil Escravista: história, mito e identidade na festa de Coroação de Rei Congo, Niterói, UFF, 1999, tese de doutorado; Patrícia A. Mulvey, The Black Brotherhoods of Colonial Brazil, New York, City College, 1976, tese de doutorado; Patrícia A. Mulvey, "Slave Confraternities in Brazil: their role in Colonial Society", The Americas, (1982), v. XXXIX, n. 1, pp. 39-68; Anderson J osé Machado de Oliveira, Devoção e Caridade: irmandades religiosas no Rio de J aneiro Imperial (1840-1889), Niterói, UFF, 1995, dissertação de mestrado; Antonia Aparecida Quintão, Lá vem o meu parente: As Irmandades de pretos e pardos no Rio de J aneiro e em Pernambuco (século XVIII), São Paulo, USP, 1997, tese de doutorado; A. J. R. Russell-Wood, "Black and Mulatto Brotherhoods in Colonial Brazil: a study in Collective Behavior", Hispanic American Historical Review, (1974), v. 54, n. 4, pp. 567-602; A. C. de C. M. Saunders, A Social History of Black Slaves and Freedmen in Portugal: 1441-1555, New York, University of Cambridge, 1982; J ulita Scarano, "Black Brotherhoods: integration or contradiction?", Luso-Brazilian Review, (1979), v. 16, n. 1, pp. 01-17; J ulita Scarano, Devoção e Escravidão: a Irmandade de Nossa Senhora do Rosário dos Pretos no Distrito Diamantino no século XVIII, São Paulo, Cia. Editora Nacional, 1976, (Brasiliana v. 357); Luiz Geraldo Silva, “Da Festa à Sedição: sociabilidades, etnia e controle social na América Portuguesa (1776-1814), História: Questões \&Debates, (1999), n. 30, pp. 83-110; Mariza de Carvalho Soares, Identidade étnica, religiosa e escravidão: os "pretos minas" no Rio de J aneiro (século VXIII), Niterói, UFF, 1997, tese de doutorado. Não é nosso objetivo, aqui, tratar detidamente o assunto. Na nossa dissertação de mestrado, intitulada O Rosário dos Homens Pretos de Santo Antônio: alianças e conflitos na História Social do Recife, 1848-1872, defendida na Unicamp, o assunto é amplamente discutido.

4 Desde sua criação, o Terço dos Henriques manteve uma forte proximidade com as Irmandades do Rosário em Pernambuco, embora sempre tenha sido uma instituição autônoma. O Terço acabou por ter uma subordinação indireta às "hierarquias do Rei do Congo", na medida em que alguns de seus oficiais eram confrades nas irmandades dos homens pretos. Apontamos, na nossa dissertação de mestrado, fontes que associam a participação de Henriques tanto nas festas de coroação do Rei do Congo, quanto a presença de alguns deles nos mais altos postos de comando das irmandades dedicadas aos homens de cor. Este grupo de milicianos, originalmente, foi formado após a Restauração Pernambucana, quando da expulsão dos holandeses no século XVII. Tratava-se de uma organização militar, criada em homenagem a participação dos negros nesta luta, sob comando de Henrique Dias.

5 Os pesquisadores clássicos sobre a cultura negra, no Brasil, insistiram muito na relação exclusiva entre as coroações do Rei do Congo, os bantu e o culto à Senhora do Rosário, especialmente centradas no grupo étnico congo, que supostamente teria o privilégio de coroar o referido rei (Ramos 1953: 56-57), (Rodrigues 1982: 32). Estes, e outros pesquisadores, fizeram suas afirmações baseando-se também nos relatos de viajantes e cronistas. Koster, por exemplo, afirmou que os senhores pernambucanos "aos negros do Congo permitiram a eleição do Rei e da Rainha [retirados] entre os indivíduos dessa nação" (Koster 1942:354).

6 Poderíamos incorporar outros antropólogos que discutem tais questões, desde os mais recentes até os mais clássicos, como Claude Levi-Strauss em $L$ 'identité, mas tal aprofundamento foge do objetivo mais panorâmico deste artigo.

7 APEJ E, Polícia Civil, PC-25, fls. 166-168.

8 IPHAN/Museu da Abolição (Recife), Irmandade de Nossa Senhora do Rosário da Freguesia de Santo Antônio do Recife - Termos da Irmandade (Livro de Atas), 1852-1871, fl. 28v.

9 Num processo de assassinato, no Rio de J aneiro, no século XIX, surgem Pedrinho e Manuel Pedro. Quando se tomaram suspeitos do 
crime, passam a ser referidos como preto Pedro e preto forro Manuel. Segundo Hebe Maria Matos, isto foi uma ação para desqualificar os acusados. Entre uma e outra forma de referência, as identidades étnicas e sociais tiveram fronteiras muito cambiáveis, no nosso ponto de vista. A conveniência foi o mote da classificação. (Mattos 1998: 130).

10 Diário de Pernambuco, 20.09.1848.

11 APEJ E, Polícia Civil, PC-25, fl. 168.

12 Idem, fls. 166-167.

13 Diário de Pernambuco, 27.05.1851. 
Marcelo Mac Cord

\section{REFERÊNCIAS BIBLIOGRÁFICAS}

BARBALHO, Nelson. 1982. Cronologia Pernambucana: subsídios para a história do agreste e do sertão - $1631-1654$. Recife: Fundação de Desenvolvimento Municipal do Interior de Pernambuco. v. 3.

BARTH, Fredrik. 1969. "Introduction”. In Fredrik Barth (edictor). Ethnic Groups and Boundaries: the social organization of culture difference. Oslo: Universitetsforlaget.

CARVALHO, Marcus J . M. de. 1998. Liberdade: rotinas e rupturas do escravismo, Recife,1822-1850. Recife: Editora UFPe. COELHO, Virgílio. 1997. “Em busca da Kábàsà: uma tentativa de explicação da estrutura político-administrativa do ‘Reino de Ndòngò'"'. Estudos Afro-Asiáticos 32: 135-162.

COSTA, Francisco Augusto Pereira da. 1984. Anais Pernambucanos 1824-1833. Recife: FUNDARPE. v. 9.

FLORENTINO, Manolo Garcia. 1995. Em Costas Negras: uma história do tráfico Atlântico de escravos entre a África e o Rio de J aneiro (séculos XVIII e XIX). Rio de J aneiro: Arquivo Nacional.

HELLER, Agnes. 1992. O Cotidiano e a História. Rio de J aneiro: Paz e Terra.

KARASCH, Mary C. 2000. A Vida dos Escravos no Rio de J aneiro: 1808-1850. São Paulo: Cia. das Letras.

KOSTER, Henry. 1942. Viagens ao Nordeste do Brasil. São Paulo: Cia. Editora Nacional.

LOPES, Nei. /s.d./. Dicionário Bantu do Brasil: repertório etimológico de vocábulos brasileiros originários dos Centro, Sul, Leste e Sudoeste Africanos. Rio de J aneiro: Prefeitura da Cidade do Rio de J aneiro.

MATTOS, Hebe Maria. 1998. Das Cores do Silêncio: os significados da liberdade no sudeste escravista - Brasil, século XIX. Rio de J aneiro: Nova Fronteira.

MILLER, J oseph C. 1997. “Angola central e do sul por volta de 1840”. Estudos Afro-Asiáticos 32: 07-54

NIETZSCHE, Friedrich. /s.d./. Além do Bem e do Mal ou Prelúdio de Uma Filosofia do Futuro. Rio de J aneiro: Ediouro.

OLIVEIRA, J oão Pacheco de. 1998. “Os instrumentos de bordo: expectativas e possibilidades de trabalho do antropólogo em laudos periciais". In J oão Pacheco de Oliveira (org.). Indigenismo e Territorialização: poderes, rotinas e saberes coloniais no Brasil contemporâneo. Rio de J aneiro: Contracapa.

OLIVEIRA, Maria Inês Côrtes. 1997. “Quem eram os ‘negros da Guiné’? A origem dos africanos na Bahia”. Afro-Asia 19/ 20: 37-73.

PIO, Fernando. 1935. Meu Recife de Outrora. Recife: Casa Mozart.

POUTIGNAT, Philippe \&STREIFF-FENART, J ocelyne. 1998. Teorias da Etnicidade. São Paulo: Ed. UNESP.

RAMOS, Arthur. 1953. O Folk-lore Negro do Brasil: demopsychologia e psychanalyse. Rio de J aneiro: Civilização Brasileira. REIS, J oão J osé. 1986. Rebelião Escrava no Brasil: a história do levante dos malês, 1835. São Paulo: Brasiliense.

RIBEIRO, René. 1948/49. “O negro em Pernambuco”. Revista do Instituto Arqueológico, Histórico e Geográfico de Pernambuco XLII: 07-25.

RODRIGUES, Nina. 1982. Os Africanos no Brasil. São Paulo/Brasília: Ed. Nacional/Ed. UnB. 
SILVA, Eduardo. 1997. Dom Obá II D'África, o Príncipe do Povo: vida, tempo e pensamento de um homem livre de cor. São Paulo: Cia. das Letras.

SILVA, Leonardo Dantas da. 1988a. "A instituição do Rei do Congo e sua presença nos maracatus". In Leonardo Dantas da Silva (org.). Estudos sobre a Escravidão Negra. Recife: FUNDAJ /Ed. Massangana. v.2. . 1988b. Alguns Documentos para a História da Escravidão. Recife: Ed. Massangana.

SILVA, Luiz Geraldo. 1999. “Da Festa à Sedição: sociabilidades, etnia e controle social na América Portuguesa (17761814)". História: Questões \&Debates 30: 83-110.

SOARES, Mariza de Carvalho Soares. 1997. Identidade étnica, religiosa e escravidão: os "pretos minas" no Rio deJ aneiro (século VXIII). Tese de doutorado. Niterói: UFF.

SLENES, Robert W. 1991/92. “'Malungu, Ngoma vem!': África coberta e descoberta do [sic: leia-se "no"] Brasil” . Revista USP 12: 48-67.

.1999. Na Senzala, Uma Flor: esperanças e recordações na formação da família escrava. Brasil, sudeste, século XIX. Rio de J aneiro: Nova Fronteira.

THORNTON, J ohn. 1997. "As guerras civis no Congo e o tráfico de escravos: a história

e a demografia de 1718 a 1844 revisitadas". Estudos Afro-Asiáticos 32: 55-74.

TOLLENARE, Louis-François. 1978. Notas Dominiciais. Recife: Secretaria de Educação e Cultura do Estado Pernambuco.

TORRES, Cláudia Viana. 1997. Um reinado de Negros em um Estado de Brancos: organizações de escravos urbanos em Recife no Final do século XVIII e início do século XIX (1774-1815). Dissertação de mestrado. Recife: UFPe.

WEBER, Max. 1994. Economia e Sociedade: fundamentos da sociologia compreensiva. Brasília: Editora da UnB. v. 1. 
Marcelo Mac Cord

Identidades Étnicas, Irmandade do Rosário e Rei do Congo: sociabilidades cotidianas recifenses - século XIX RESUMO

Buscamos entender, neste artigo, a plasticidade das identidades étnicas na história social da Irmandade do Rosário dos Pretos da freguesia de Santo Antônio do Recife. A presença de diversas etnias, no corpo confraternal, foi balizada por fortes hierarquias e algumas exclusões. As referências étnicas africanas acabaram remodelando-se às realidades sócio-históricas e culturais recifenses, possibilitando a construção de novas redes de compromisso e solidariedade entre as gentes de cor - aportadas e/ou nascidas em solo pernambucano. A Irmandade do Rosário dos Pretos da freguesia de Santo Antônio do Recife é o locus privilegiado para entendermos tais questões.

PALAVRAS-CHAVE: identidades étnicas; irmandades leigas

Ethnic Identities, Irmandade do Rosário and the King of Congo: Recife's daily sociabilities - 19th. Century ABSTRACT

This article aims to understand the plasticity of Rosário dos Pretos Brotherhood's ethnic identity, its unfolding in social history. This brotherhood belongs to the freguesia of Santo Antônio do Recife (Pernambuco, Brazil). The presence of several ethnic groups in this brotherhood is marked by powerful hierarchies and some exclusions. The African ethnic references have remodeled themselves in reference to the social-historical and cultural reality of Recife, which made possible the construction of new alliances and solidary networks among colored people born or recently arrived in Pernambuco. The brotherhood of Rosário dos Pretos is a privileged locus of analysis for us to realize these questions.

KEY WORDS: ethnic identity, black brotherhood 